\title{
LACTIC ACID AND PH LEVELS AS THE AUTHENTIC AND RELIABLE DIAGNOSTIC TOOLS FOR THE ASSESSMENT OF THE FETAL ACIDEMIA
}

\author{
Nusrat Zareen, Muhammad Saleem Khanzada, Rukhsana Rubeen, Zakir Jalal Khanzada, Syed \\ Touseef Ahmed, Shaheen Sharaf Shah and Syed Saud Hasan
}

\begin{abstract}
OBJECTIVE: To identify the importance of acidemia in distressed neonates with its diagnosis on confirmative basis and to evaluate its severity by the estimation of lactic acid (LA), pH, bicarbonate $\left(\mathrm{HCO}_{3}^{-}\right)$ions and hemoglobin $(\mathrm{Hb})$ in comparison to subjective criteria like Apgar score $(0-10)$, fetal heart rate $120-160$ beats per minute and meconium staining of liquor which provides vague diagnosis.

METHODS: This study was conducted at Basic Medical Sciences Institute, located at Jinnah Postgraduate Medical Centre Karachi, Sindh - Pakistan. It comprised of $\mathbf{4 0}$ full term neonates with acidemia without any other co-morbidity and $\mathbf{4 0}$ matching controls.

RESULTS: In this study, fetal arterial blood acid base analysis showed that LA levels were significantly high $(\mathrm{P}=0.001)$ and $\mathrm{pH}, \mathrm{HCO}_{3}{ }^{-}$and $\mathrm{Hb}$ levels were significantly low $(\mathrm{P}=0.001)$ in acidotic neonates as compared to controls.

CONCLUSION: High LA levels with decreased $\mathrm{pH}, \mathrm{HCO}_{3}{ }^{-}$and $\mathrm{Hb}$ are associated with acidemia in newborns, which reveal confirmative diagnosis with comparison to subjective criteria for diagnosis of acidemia.
\end{abstract}

KEY WORDS: Fetal acidemia. Acid base balance. Lactic acid.

\section{INTRODUCTION}

The $26^{\text {th }}$ Royal College of Obstetricians and Gynecologists Study Group on intrapartum fetal surveillance in 1993 recommended measurement of acid base balance of the umbilical cord arterial and venous blood after delivery as measure of the fetal response to labor. ${ }^{1}$ The cord acid base assessment provides an objective measure of neonatal condition at delivery. ${ }^{1-7}$ Acute fetal distress during labor remains one of the primary objectives of obstetrical surveillance. As there is a weak correlation between the biochemical parameters that provide more reliable diagnosis (i.e. lactic acid, $\mathrm{pH}$ and $\mathrm{HCO}_{3}^{-}$) in comparison to the subjective criteria for fetal acidemia i.e. Apgar score (0-10), fetal heart rate $120-160$ beats per minute (bpm) and meconium staining of liquor. Acute fetal distress induces asphyxia leading to hypoxia of most of the organs which causes increase in lactic acid level, along with alteration in $\mathrm{pH}$ and $\mathrm{HCO}_{3}{ }^{-8}$. Most of the parameters used for fetal monitoring have good sensitivity but low specificity. ${ }^{9,10}$ Now a days, umbilical cord vessel acid base analysis is increasingly employed as an end point in the study of antepartum and intrapartum care. ${ }^{11}$ It is the most accurate method of quantifying the acid-base status of the fetus at the moment of delivery $^{12}$ and is an important adjunct for determining the extent and cause of fetal acidosis at delivery. ${ }^{13}$ The cord acid base assessment provides an objective measure of neonatal conditions at delivery. ${ }^{11}$ The only scientific, objective mean of diagnosis of fetal asphyxia at delivery is through umbilical blood acid base studies. ${ }^{12}$ Umbilical cord blood sampling is regarded as the "gold standard" in the analysis of the biochemical state of the fetus. Umbilical cord blood acid base analysis has emerged in recent years as a method of assessing the newborn objectively because other predictors of outcome, including the Apgar score, are based on subjective criteria and they correlate poorly with neonatal outcome. ${ }^{13-14}$

\section{SUBJECTS AND METHODS}

This study was conducted at the Basic Medical Sciences Institute, Jinnah Postgraduate Medical Centre Karachi, Sindh - Pakistan. The control samples of cord blood were collected from 40 normal term neonates just after the delivery. Acidemic group of 40 neonates included in the study were those who showed any subjective or objective sign of fetal distress. The newborns were chosen from the labor room of Gynecology and Obstetrics Department of JPMC, Karachi. The fetal acidotic subjects included in the study were 40 newborn infants with subjective or objective signs of 
fetal distress i.e. fetal heart rate $(F H R)<120$ (bpm) or FHR > 160 bpm, history of meconium staining of liquor or Apgar score below 7 at 1 minute and at 5 minutes intervals. Only those neonates were included in control group who were born as full term delivery of at least 36-40 weeks gestational period with no subjective signs of fetal distress i.e. Apgar score $>7$ in 1 minute, normal FHR (120-160 bpm) and no history of liquor staining with meconium. Those neonates were not included in study with any congenital abnormality, low birth weight or small for date or their mothers suffering from any cardiac disease, renal disease, diabetes mellitus, pregnancy induced hypertension, any hepatic or respiratory problem or any acute illness prior to the labour. Soon after delivery before the first breath of baby, $2 \mathrm{ml}$ blood was taken from umbilical artery in centrifuge tube containing sodium floride/EDTA in ratio $2: 1$, used for lactic acid estimation by enzymatic colorimetric method which is method of choice .A corning-248 blood gas analyzer (Ciba Corning Diagnostics, Ltd.) was used to estimate the level of $\mathrm{pH}$ and $\mathrm{HCO}_{3}{ }^{-}$. This machine is self calibrating and another 2 $\mathrm{ml}$ of umbilical blood sample collected in bottle containing $3 \mathrm{mg}$ EDTA used for $\mathrm{Hb}$ estimation done by cynamet hemoglobin method.

\section{RESULTS}

In this study, 40 full term newborns of age about 3640 weeks with acidemia were compared with 40 full term age matched healthy newborns as controls during a period of 6 months. Table I presents the comparison between the two groups. There was marked difference between the values of control and acidotic groups. The lactic acid was significantly higher in acidotic group, with mean of $1.87 \pm 0.075 \mathrm{mmol} / \mathrm{l}$ and in the controls, mean was $0.92 \pm 0.035 \mathrm{mmol} / \mathrm{l}(\mathrm{p}=<0.001)$ while $\mathrm{pH}$ and $\mathrm{HCO}-3$ levels were low in acidemic group with the mean of $7.13 \pm 0.009 \quad(p=0.01)$, $18.43 \pm 0.498(p=<0.001)$ respectively in comparison to control group in which the mean was $7.13 \pm 0.009$, $22.70 \pm 0.526$ respectively showing the significant importance with the application of chi-square test. Hemoglobin $(\mathrm{Hb})$ concentration was low in acidotic group, which also may be the contributing factor in neonatal acidemia. Table II shows the comparison between acidemic neonates with controls for the presence of subjective criteria. Here the control neonates showed normal findings like Apgar score $>7$, FHR in between 120-160 bpm and no history of meconium staining. While 23 of acidotic group had Apgar score $<7(57.5 \%), 13$ neonates with meconium staining (32.5\%) and 17(42.5\%) showed abnormal FHR < 120 or $>160$ bpm.
TABLE I:

COMPARISON BETWEEN MEAN VALUES OF DIFFERENT PARAMETERS OF CONTROL AND ACIDEMIC NEONATES

\begin{tabular}{|l|c|c|c|}
\hline \multicolumn{1}{|c|}{ Variable } & $\begin{array}{c}\text { Control } \\
\text { Neonates } \\
(\mathbf{n}=\mathbf{4 0})\end{array}$ & $\begin{array}{c}\text { Acidemic } \\
\text { Neonates } \\
(\mathbf{n}=\mathbf{4 0})\end{array}$ & $\begin{array}{c}\mathbf{P} \\
\text { Value }\end{array}$ \\
\hline Lactic acid & $0.92 \pm 0.035$ & $1.87 \pm 0.075$ & $<0.001$ \\
\hline $\mathrm{pH}$ & $7.30 \pm 0.009$ & $7.13 \pm 0.009$ & 0.01 \\
\hline $\mathrm{HCO3-}$ & $22.70 \pm 0.526$ & $18.43 \pm 0.498$ & $<0.001$ \\
\hline $\mathrm{Hb}(\mathrm{gm} / \mathrm{dl})$ & $14.94 \pm 0.214$ & $14.01 \pm 0.213$ & 0.01 \\
\hline
\end{tabular}

TABLE II:

COMPARISON OF SUBJECTIVE SIGNS IN ACIDOTIC NEONATES WITH CONTROL GROUPS

\begin{tabular}{|l|c|c|c|}
\hline \multicolumn{1}{|c|}{ Variable } & Controls & $\begin{array}{c}\text { Acidemic } \\
\text { Group }\end{array}$ & Percentage \\
\hline Apgar Score & $>7^{\star \star}$ & $23^{*}$ & $57 \%$ \\
\hline $\begin{array}{l}\text { Fetal Heart } \\
\text { Rate }\end{array}$ & $\begin{array}{c}120-160 \\
\text { Bpm }\end{array}$ & $17^{*}$ & $42.5 \%$ \\
\hline $\begin{array}{l}\text { Meconium } \\
\text { Staining }\end{array}$ & $-V e$ & $13^{*}$ & $32.5 \%$ \\
\hline
\end{tabular}

* Number of neonates showing abnormal subjective signs.

** Infants in good condition, combine score 8-10

Infant in poor condition had combine score 0-2 (Gregg and Weiner, 1993)

\section{DISCUSSION}

This study revealed how little attention was paid to confirm fetal academia on authentic basis. Acidotic neonates with abnormal Apgar score were seen in $57.5 \%$, meconium staining in $32.5 \%$ and abnormal fetal heart rate in $42.5 \%$ in this study population. Different investigators have reported different frequency rates in subjective criteria for fetal acidemia. Only 5\% of newborns with meconium staining were acidotic at the time of delivery because the Apgar score does not reflect the fetal acid base status, it cannot be used as an index of academia. In one study, $37 \%$ neonates with Apgar score below 1 minute had normal $\mathrm{pH}$ and in another study, $73 \%$ acidotic babies had normal Apgar scores (Blackstone \& Young, 1993). ${ }^{9}$ Yeoman, et al in $1985^{2}$ reported that $53 \%$ had 
acidemia with meconium staining while other authors have concluded that mostly meconium staining is associated with acidosis and neurologic depression. Blackstone \& Young (1993) observed 36-60\% FHR problems with acidosis. Meanwhile, Goldaber \& Gilstrap had also observed that newborns who had abnormal FHR, $80 \%$ were not acidemic at birth while $21 \%$ had acidosis. ${ }^{7}$ This study was designed to determine and confirm the acid base disturbances of blood during intrapartum period in the fetus. These changes may be very harmful for the neonates if not recognized and treated properly. In our population, at present, there is very little orientation about these disturbances, especially in the newborns. No significant association was found between a pathological CTG recording, fetal Apgar score and acidemia. An increase in cesarean section rate in babies with pathological CTG stresses on the need for additional test to differentiate hypoxic from non-hypoxic fetuses thus avoiding unnecessary intervention. ${ }^{15}$ Several studies have reported normal data for vaginal delivery for acid base analysis., 2,16,17 In this study, the mean values in control population for acid base are in complete agreement with the mean values given in the studies of above authors but the acidemic values are more marked. The probable reason may be that there is still no any proper orientation about fetal acidemia during intrapartum period and its management. Fetal metabolic acidosis is reflection of dysfunction of fetoplacental unit, which results in anaerobic glycolytic pathway and increase production of lactate. The lactic acid is buffered in the fetus by sodium bicarbonate and some of the excess lactic acid is also buffered by hemoglobin. ${ }^{18}$ This study is in complete agreement with the above study because fetal acidemia is associated with metabolic acidosis which resulted in increased lactic acid, decreased bicarbonate and $\mathrm{pH}$ values. The severity of metabolic acidosis usually reflects the degree of the fetal hypoxic insult. ${ }^{19}$ Our observations are in accordance with above mentioned research workers and values are highly significant $(P<0.001)$ where decrease in bicarbonate levels, a high lactate level and fall in $\mathrm{pH}$ were observed. Regarding fetal anemia of newborn with massive fetomaternal hemorrhage. the fetal blood loss led to severe late decelerations in the antepartal CTG. The newborns showed a marked anemia ( $\mathrm{Hb} 4.9 \mathrm{~g} \%)$ and a rapidly progressive heart failure. ${ }^{8,12}$ Although, in this study, the fetuses were not grossly anemic and it was an incidental finding, but it appears that there may be some fetomaternal hemor- rhage that is consequently influencing the CTG and other subjective parameters of fetal distress.

\section{REFERENCES}

1. Sykes GS, Molloy PM, Johnson P, Stirrat GM and Turnbull AC. Fetal distress and the condition of newborn infants.Br Med J. 1983; 287:943-45.

2. Yeomans ER, Hauth JC, Gilstrap III LC and Strickland DM. Umbilical cord $\mathrm{pH}, \mathrm{PCO}_{2}$ and bicarbonate following uncomplicated term vaginal deliveries. Am J Obstet Gynecol. 1985; 151:798800.

3. Low JA. The role of blood gas and acid base assessment in the diagnosis of intrapartum fetal asphyxia. Am J Obstet Gynaecol. 1988; 159:123540.

4. Dickinson JE, Eriksen NL, Meyer BA and Parisi VM. The effect of preterm birth on umbilical cord blood gases. Obstet Gynecol. 1992; 79: 575-78.

5. Duerbeck NB, Chaffin DG and Seeds JW. A practical approach to umbilical artery $\mathrm{pH}$ and blood gas determinations. Obstet Gynaecol. 1992; 79:959-62.

6. Goldaber KG and Gilstrap II LC. Correlation between obstetric clinical events and umbilical cord blood acid base and blood gas values. Clin Obstet Gynecol. 1993; 36: 47-59.

7. Gregg AR and Weiner CP. Normal umbilical arterial and venous acid base and blood gas values. Clin Obstet Gynecol. 1993; 36:24-32.

8. Johnson JWC, Richards DS, Wagaman RA. The case for routine umbilical acid base studies at delivery. Am J Obstet Gynecol. 1990; 162: 621-25.

9. Blackstone $\mathrm{J}$ and Young BK. Umbilical cord acid base values and other descriptors of fetal condition. Clin Obstet Gynecol. 1993; 36: 33-46.

10. Riley RJ and Johnson JWE. Collecting and analyzing cord blood gases. Clin Obstet Gynecol. 1993; 36:13-23.

11. Westgate J, Garibaldi JM and Greene KR. Umbilical cord blood gas analysis at delivery: A time for quality data. $\mathrm{Br} \mathrm{J}$ Obstet Gynecol. 1994; 1101: 1054-63.

12. Richards DS and Johnson JWC. The practical implications of cord blood acid base studies. Clin Obstet Gynecol. 1993; 36:91-8.

13. Modarressnejad V. Umbilical cord blood $\mathrm{pH}$ and risk factors for acidemia in neonates in Kerman. East Mediterr Health J. 2005;11(1-2): 96-101.

14. Uzan S, Berkane N, Verstrae L, et al. Acid base 
balance in the fetus during labor: Pathophysiology and exploration methods. J Gynecol Obstet Biol Reprod (Paris). 2003; 31(1 Suppl): 1568-78.

15. Sheikh SM, Kamruddin A, Setna F and Riaz T. Role of pathological cardiotocography in evaluating fetal well being. J Coll Physicians Surg Pak. 2006; 16(6): 404-7

16. Kecskes Z. Large fetomaternal hemorrhage: Clinical presentation and outcome. J Matern Fetal Neonatal Med. 2003; 13(2): 128-32.

17. Thorp JA, Sampson JE, Parisi VM, et al. Routine umbilical cord blood gas determinations? Am J Obstet Gynecol. 1989; 161: 600-605.

18. Brar HS, Wong MK, Kirschbaum TH and Paul RH. Umbilical cord acid base changes associated with perinatal cardiac failure. Am J Obstet Gynecol. 1988; 158: 511-18.

19. Low JA, Panagiotopoulos $C$ and Derrick EJ. Newborn complications after intrapartum asphyxia with metabolic acidosis in the preterm fetus. Am J Obstet Gynecol. 1995; 172: 805-10.

\begin{tabular}{|l|}
\multicolumn{1}{|c|}{ AUTHOR AFFILIATION: } \\
Dr. Nusrat Zareen (Corresponding Author) \\
Assistant Professor, Department of Physiology \\
Dow Medical College Karachi, Sindh-Pakistan. \\
Email: khanzadasaleem@yahoo.com \\
Dr. Muhammad Saleem Khanzada \\
Assistant Professor \\
Department of Pathology \\
Sindh Medical College, Karachi, Sindh-Pakistan. \\
Dr. Rukhsana Rubeen \\
Assistant Professor \\
Department of Biochemistry \\
Dow Medical College, Karachi, Sindh-Pakistan. \\
Dr. Zakir Jalal Khanzada \\
University of North Dakota, USA \\
Dr. Syed Touseef Ahmed \\
Associate Professor \\
Department of Physiology \\
Dow Medical College, Karachi, Sindh-Pakistan. \\
Prof. Shaheen Sharaf Shah \\
Professor of Pharmacology \\
Liaquat University of Medical \& Health Sciences, \\
Jamshoro, Sindh-Pakistan. \\
Dr. Syed Saud Hasan \\
Associate Professor \\
Department of Pharmacology \\
Dow Medical College, Karachi, Sindh-Pakistan. \\
\hline
\end{tabular}

